\title{
Correction to: Melanin biosynthesis in bacteria, regulation and production perspectives
}

\author{
María Elisa Pavan ${ }^{1} \cdot$ Nancy I. López ${ }^{1,2} \cdot$ M. Julia Pettinari ${ }^{1,2}$ (D)
}

Published online: 7 January 2020

(C) Springer-Verlag GmbH Germany, part of Springer Nature 2020

\section{Correction to: Applied Microbiology and Biotechnology https://doi.org/10.1007/s00253-019-10245-y}

The original version of this article contains error for some of the authors corrections were not included during correction stage especially for Table 1 .

The original article has been corrected.

Publisher's note Springer Nature remains neutral with regard to jurisdictional claims in published maps and institutional affiliations.

The online version of the original article can be found at https://doi.org/ 10.1007/s00253-019-10245-y

\footnotetext{
Nancy I. López

nan@qb.fcen.uba.ar

$\triangle$ M. Julia Pettinari jul@qb.fcen.uba.ar

1 Departamento de Química Biológica, Facultad de Ciencias Exactas y Naturales, Universidad de Buenos Aires, Buenos Aires, Argentina

2 IQUIBICEN-CONICET, Facultad de Ciencias Exactas y Naturales, Universidad de Buenos Aires, Buenos Aires, Argentina
} 


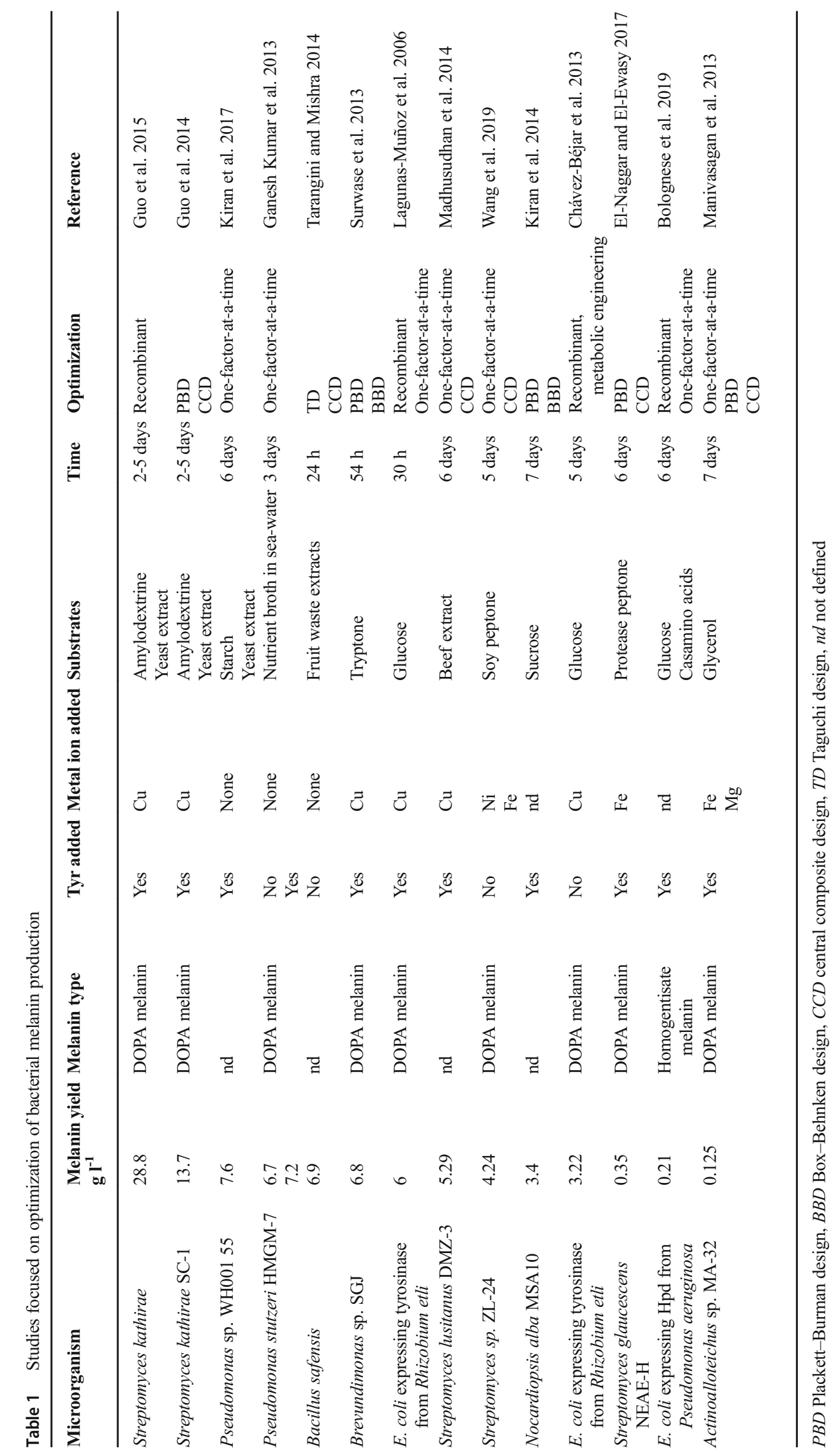

